\title{
Relationship between sickness presenteeism and awareness and presence or absence of systems for return to work among work- ers with mental health problems in Japan: an Internet-based cross-sectional study
}

\author{
Shotaro DokI ${ }^{1}$, Shinichiro Sasahara ${ }^{2}$, Shun Suzuki ${ }^{1}$, Yasuhito Hirai ${ }^{1}$, Yuichi Oi ${ }^{2}$, \\ Kazuya USAMI $^{2}$ and Ichiyo MATSUZAKI ${ }^{2,3}$ \\ ${ }^{1}$ Graduate School of Comprehensive Human Sciences, University of Tsukuba, Japan, ${ }^{2}$ Faculty of Medicine, University \\ of Tsukuba, Japan and ${ }^{3}$ International Institute for Integrative Sleep Medicine, University of Tsukuba, Japan
}

\begin{abstract}
Relationship between sickness presenteeism and awareness and presence or absence of systems for return to work among workers with mental health problems in Japan: an Internet-based cross-sectional study: Shotaro Dokı, et al. Graduate School of Comprehensive Human Sciences, University of Tsukuba-Objectives: The objective of this study was to clarify the relationship between sickness presenteeism and the degree of awareness of company regulations regarding financial compensation for absenteeism. Methods: An Internet-based survey of 258 full-time workers who had more than 28 days of sickness absence due to mental health problems was conducted. Workers were categorized as having either low or high sickness presenteeism, and awareness and presence or absence of systems for return to work and duration of financial compensation were compared between groups. Results: The following factors were significantly related to high sickness presenteeism based on logistic regression analyses: working for a private company (odds ratio [OR] $=2.57 ; 95 \%$ confidence interval $[\mathrm{Cl}]=1.10-5.99)$; recognition of a gradual resumption system (OR=3.89, 95\% Cl=1.02-14.81); and awareness regarding the duration of financial compensation (OR=1.04, 95\% Cl=1.01-1.07). Conclusions: No relationship was found between mental sickness presenteeism and presence or absence of systems for return to work in our multivariate analysis; however, a relationship was apparent between sickness presenteeism and characteristics of the workers' companies. These results are expected to contribute to research involving human resources and occupational health.
\end{abstract} (J Occup Health 2015; 57: 532-539)

Received Mar 25, 2015; Accepted Jul 27, 2015

Published online in J-STAGE Sep 4, 2015

Correspondence to: S. Sasahara, Faculty of Medicine, University of Tsukuba, Japan 1-1-1 Tennodai, Tsukuba, Ibaraki 305-8575, Japan (e-mail:s-sshara@md.tsukuba.ac.jp)
Key words: Company regulations, Mental disorders, Return to work, Rules of employment, Sickness presenteeism

In recent years, the mental health of workers has received a lot of attention, and many studies have been conducted on the topic. Deterioration in the mental health of workers can result in sick leave. Previous studies have indicated that the mean duration of sick leave for workers with mental depression is about 3 to 6 months ${ }^{1,2)}$. When workers take sick leave, the company loses human resources, and the International Labour Organization reported that sick leave due to mental health costs companies in the United States about 200 billion USD annually ${ }^{3}$. In order to minimize such losses, appropriate measures should be taken to prevent sickness. Sickness presenteeism, the act of working while sick, poses a similar problem, because even though such workers are present, their performance levels tend to be markedly lower.

Aronson et al. reported that one-third of the workers they studied had attended work at least twice in the preceding year despite thinking that they should have taken sick leave. Aronsson et al. also reported a relationship between low income and sickness presenteeism ${ }^{4}$. According to Sweden's regular market survey, sickness presenteeism was found in about $53 \%$ of a sample of 3,136 workers. Furthermore, sickness presenteeism is reportedly associated with difficulties in staff replacement, time pressure, insufficient resources, and poor personal finances ${ }^{5)}$. Sickness presenteeism has also been reported to be associated with factors such as long working hours, female gender, financial instability, low education, and poor physical health ${ }^{6-8)}$. Moreover, sickness presentee- 
ism can lead to an increased risk of depression ${ }^{9)}$, and wage loss has been reported to be more closely related to poor mental than to poor physical health ${ }^{10)}$. Based on these studies, poor mental health is generally perceived as a personal problem; however, mental illness is typically the result of not only personal but also environmental factors.

A previous study on improving sickness presenteeism indicated that depressed mood, but not sickness presenteeism, was improved by cognitive behavioral therapy intervention provided via telephone consultation $^{11)}$. Although interventions in the social and physical work environment had no effect on sickness presenteeism, they did improve work performance ${ }^{12)}$, and no definitive solution to this problem has been determined. It is unlikely that the causes of sickness presenteeism are limited to personal factors alone; rather, environmental factors such as marital status and housing tenure are also suspected of having a role $^{13)}$. Although personal factors have been investigated in relation to sickness presenteeism, rules of employment, which have a strong influence on workers, have not. Because workers are required to follow them, the rules of employment are expected to have a certain degree of influence.

Absenteeism and sickness presenteeism among workers are closely related ${ }^{7,14-16)}$. In order to reduce the absenteeism of workers in Japan, several financial compensation, gradual resumption, and trial attendance systems have been implemented. However, few studies have been conducted on the relationship between workers' mental health and rules of employment. In Japan, not all workers are aware of the presence of financial compensation, gradual resumption, and trial attendance systems because each company has its own in-house systems. Furthermore, the nature of service differs depending on the size of the business. Therefore, the aim of the present study was to investigate the relationship between sickness presenteeism and rules of employment with regard to returning to work. The following hypotheses were tested using an Internet-based cross-sectional survey:

Hypothesis 1: Workers who are aware of financial compensation, gradual resumption, and trial attendance systems in their workplace will have low sickness presenteeism.

Hypothesis 2: Workers whose workplaces have financial compensation, gradual resumption, and trial attendance systems will have low sickness presenteeism.

\section{Subjects and Methods}

\section{Subjects}

The present study was part of the Financial Compensation for Absenteeism and Presenteeism Study (FCAPS), which aimed to investigate the relationship between absenteeism/presenteeism and company regulations such as financial compensation. We conducted an Internet-based cross-sectional survey on June 12-13, 2014. All data were collected by the Internet research company MACROMILL (http://www. macromill.com/). As of June 1, 2014, MACROMILL had $1,167,915$ registered members in Japan ${ }^{17)}$. We randomly sent questionnaires via e-mail to possible respondents and collected responses until the target sample size was obtained. Randomization was performed by a computerized block randomization procedure. Based on the FCAPS data (total sample size of the Internet-based study: 518), we evaluated the effect of company regulations on workers who had more than 28 days of sickness absence.

\section{Survey items}

Survey items were used to assess age, sex, type of organization (private/public), occupation, managerial position (yes/no), company size, working hours per month, duration of sick leave, awareness of systems for return to work, and sickness presenteeism.

\section{Company size}

We asked about the current number of employees in the workplace of each survey participant. To categorize the size of a company, we used the same definition as used by several regulatory systems regarding the operation of companies in Japan: small-sized company, 1-49 employees; medium-sized company, 50-999 employees; and large-sized company, $\geq 1,000$ employees.

\section{Systems for return to work}

Three systems are widely used in Japan to help individuals return to work; to investigate these systems, the following survey questions were used in this study: (1) "Does your company have a financial compensation system (monetary compensation period) for sick or other types of leave from work? If yes, how long is the compensation period?"; (2) "Does your company have a system that allows you to work for a shorter time when you first return from sick or other types of leave from work (gradual resumption system)?"; and (3) "Does your company have a training system, for example, for performing an amount of work that is similar to the actual work expected or for commuting from your home to the company, that helps you return to work from sick or other types of leave (trial attendance)?"

\section{Mental sickness presenteeism}

Based on results from a previous study ${ }^{4}$, the following question was used to evaluate sickness presenteeism: "In the past 12 months, have you attended work 
despite feeling that you really should have taken sick leave due to the state of your mental health?" Responses were given on the following 4-point scale: (1) "No"; (2) "Yes, once"; (3) "Yes, 2 to 5 times"; or (4) "Yes, more than 5 times". Workers whose response was either (1) or (2) were categorized into a low sickness presenteeism group, and workers whose response was either (3) or (4) were categorized into a high sickness presenteeism group.

\section{Statistical analyses}

Responses to the following items were then compared between the low and high sickness presenteeism groups using Pearson's chi-square test: background characteristics, awareness of each system for return to work, and presence/absence of systems for return to work. In addition, mean working hours were compared between the groups using a $t$ test. Regarding sickness presenteeism, the odds ratios (ORs) and 95\% confidence intervals (CIs) were calculated for each factor using binary logistic regression analysis and controlled for gender, age, company size, private/public organization, managerial role and working hours. The following four models were constructed to analyze each variable: model 1, awareness of systems for return to work; model 2, presence of systems for return to work; model 3, presence of systems for return to work with a duration (months) of financial compensation; and model 4, both awareness and presence of a duration (months) of financial compensation. To combine the awareness and presence of system variables, the response "I am unaware of these systems" was combined with that indicating absence of systems for return to work in model 4 . If a respondent indicated that there was "no compensation period", the duration (months) of financial compensation was defined as 0 . The level of significance was set at 0.05 . All analyses were performed using IBM SPSS Statistics for Windows Version 22 (IBM Corp., Armonk, NY, USA).

\section{Sample size}

We calculated the sample size with $\mathrm{G}^{*}$ Power $^{18)}$. Given a one-sided alpha of 0.05 , an estimated effect size $\left(\mathrm{f}^{2}\right)$ of $0.15,13$ predictors, and a valid response rate of $70 \%$, at least 187 participants were needed to achieve a power of 0.80 .

\section{Ethical considerations}

Before the surveys were distributed, consent to participate was obtained from all workers, who had been fully informed about the purpose of the study and the use and management of the data. Personal information was anonymized, and the data collected from the participants were only used for the purposes of this study. The present study was approved by the ethics committee at the University of Tsukuba (Approval Number: 691-1).

\section{Results}

\section{Sample characteristics}

The participants comprised 258 full-time workers who had more than 28 days of sickness absence due to mental health problems. All workers submitted a medical certificate to justify their absences. Of these 258 workers, 15 were excluded because their reported total working hours per month did not match the number of holidays and days of leave from work (e.g., the number of holidays and leave from work was 28 , and the number of total work hours was 120) to a reasonable degree. Thus, 243 workers were included in the analysis. Table 1 shows the basic characteristics of the study participants.

\section{Sickness presenteeism}

Regarding the question "In the past 12 months, have you attended work despite feeling that you really should have taken sick leave due to the state of your mental health?", 92 workers $(38 \%)$ answered either (1) "No" or (2) "Yes, once". These workers were regarded as the low sickness presenteeism group. The remaining 151 workers (62\%) answered either (3) "Yes, 2 to 5 times" or (4) "Yes, more than 5 times". These workers were regarded as the high sickness presenteeism group (Table 1).

Awareness and presence or absence of systems for return to work and sickness presenteeism

A comparison between the low and high sickness presenteeism groups regarding awareness and presence or absence of systems for return to work is shown in Table 2. More workers in the high sickness presenteeism group worked for private companies $(p=0.022)$. No other significant differences were observed between the groups.

\section{Multivariate analysis}

ORs were calculated for each factor (sex, age, company size, type of organization, managerial position, working hours per month, financial compensation, gradual resumption, and trial attendance) in the high sickness presenteeism group. Significant relationships were observed between high sickness presenteeism and working for a private company $(\mathrm{OR}=2.57$; 95\% CI=1.10-5.99), and between high sickness presenteeism and awareness of both gradual resumption $(\mathrm{OR}=3.89,95 \% \mathrm{CI}=1.02-14.81)$ and duration of financial compensation $(\mathrm{OR}=1.04,95 \% \mathrm{CI}=1.01-1.07)$. No other significant relationships were found (Table 3 ). 
Table 1. Study characteristics $(n=243)$

\begin{tabular}{|c|c|c|c|c|}
\hline & $\mathrm{n}$ & $(\%)$ & Mean & (SD) \\
\hline \multicolumn{5}{|l|}{ Sex } \\
\hline Male & 194 & $(79.8)$ & & \\
\hline Female & 49 & $(20.2)$ & & \\
\hline \multicolumn{5}{|l|}{ Age } \\
\hline Total & & & 43.5 & (8.4) \\
\hline Male & & & 44.9 & (7.4) \\
\hline Female & & & 38.1 & $(10.0)$ \\
\hline \multicolumn{5}{|l|}{ Types of organization } \\
\hline Private company & 202 & $(83.1)$ & & \\
\hline Public official & 41 & $(16.9)$ & & \\
\hline \multicolumn{5}{|l|}{ Types of occupation } \\
\hline Specialized/technical & 86 & $(35.4)$ & & \\
\hline Clerical & 90 & $(37.0)$ & & \\
\hline Retail & 13 & $(5.4)$ & & \\
\hline Service industry & 20 & $(8.2)$ & & \\
\hline Security & 2 & $(0.8)$ & & \\
\hline $\begin{array}{l}\text { Agricultural forestry } \\
\text { industries and fisheries }\end{array}$ & 2 & $(0.8)$ & & \\
\hline Manufacturing & 13 & (5.4) & & \\
\hline Transportation/operator & 3 & $(1.2)$ & & \\
\hline Construction/mining & 5 & $(2.1)$ & & \\
\hline Delivery/cleaning/packaging & 1 & $(0.4)$ & & \\
\hline Other & 8 & (3.3) & & \\
\hline \multicolumn{5}{|l|}{ Managerial role } \\
\hline Yes & 46 & $(18.9)$ & & \\
\hline No & 197 & $(81.1)$ & & \\
\hline \multicolumn{5}{|l|}{ Company size } \\
\hline Small & 69 & $(28.4)$ & & \\
\hline Middle & 100 & $(41.2)$ & & \\
\hline Large & 74 & $(30.4)$ & & \\
\hline Working hours/month & & & 159.6 & $(60.8)$ \\
\hline \multicolumn{5}{|c|}{ Awareness of systems for return to work } \\
\hline Financial compensation & 217 & $(89.3)$ & & \\
\hline Gradual resumption & 187 & $(77.0)$ & & \\
\hline Trial attendance & 155 & $(63.8)$ & & \\
\hline \multicolumn{5}{|c|}{ Presence of systems for return to work } \\
\hline Financial compensation & 181 & $(74.5)$ & & \\
\hline Gradual resumption & 123 & $(50.6)$ & & \\
\hline Trial attendance & 81 & $(33.3)$ & & \\
\hline \multicolumn{5}{|l|}{ Sickness presenteeism } \\
\hline Never & 67 & $(27.6)$ & & \\
\hline Only once & 25 & $(10.3)$ & & \\
\hline $2-5$ times & 67 & $(27.6)$ & & \\
\hline More than 5 times & 84 & $(34.5)$ & & \\
\hline
\end{tabular}

$\mathrm{SD}$, standard deviation.
Characteristics of the excluded data

We also analyzed the data of the 15 workers (8 men, 7 women; mean age \pm standard deviation, $41.9 \pm 9.1$ years; mean working hours for the preceding 28 days, $142.1 \pm 65.1$ hours) excluded from the study. Among the workers in this group, two had low sickness presenteeism and 13 had high sickness presenteeism.

\section{Discussion}

We investigated the relationship between sickness presenteeism and awareness and presence or absence of systems for return to work. No relationship was found between mental sickness presenteeism and presence or absence of systems for return to work in our multivariate analysis. However, associations were apparent between high mental sickness presenteeism and the following factors: employment in a private company, awareness of a gradual resumption system, and longer duration of financial compensation.

The strength of the present study lies in the fact that awareness and presence of systems for return to work were used as independent variables. No previous study has investigated whether mental sickness presenteeism is associated with rules of employment, particularly awareness of systems for return to work after long-term leave. Prior to this study, the following personality factors were reported to be related to sickness presenteeism: long working hours, female gender, financial instability, low education, poor physical health, and time pressure ${ }^{5-8)}$. Based on the results of systematic reviews and meta-analysis, Netterstrøm et al. reported that social support decreases the risk of mental depression ${ }^{19)}$. The mental state of workers may be influenced by environmental factors, such as social support through systems for return to work, which may in turn affect sickness presenteeism. Furthermore, environmental factors can also affect the mental state of workers. One study showed that when supervisors took part in a stress education program, significant decreases in the level of psychological distress and significant increases in job performance were observed among their younger, male, whitecollar subordinates ${ }^{20)}$. Similar results were seen in another study involving supervisors and workers in the same office ${ }^{21)}$. These studies indicate that, in addition to environmental and situational factors, sickness presenteeism is also influenced by personality factors. Therefore, this study is valuable due to its focus on systems for return to work.

In the present study, Hypothesis 1 was "Workers who are aware of financial compensation, gradual resumption, and trial attendance systems in their workplace will have low sickness presenteeism". This hypothesis was not supported by our results. 
Table 2. A comparison among the factors of sickness presenteeism, sex, types of organization, management, company size, and working hours $(n=243)$

\begin{tabular}{|c|c|c|c|c|c|c|c|}
\hline & \multicolumn{6}{|c|}{ Sickness presenteeism } & \multirow[b]{3}{*}{$p$} \\
\hline & \multicolumn{3}{|c|}{ High } & \multicolumn{3}{|c|}{ Low } & \\
\hline & $\mathrm{n}$ & Mean & (SD) & $\mathrm{n}$ & Mean & (SD) & \\
\hline \multicolumn{8}{|l|}{ Sex } \\
\hline Male & 118 & & & 76 & & & $0.400^{\mathrm{a}}$ \\
\hline Female & 33 & & & 16 & & & \\
\hline \multicolumn{8}{|l|}{ Types of organization } \\
\hline Private company & 132 & & & 70 & & & $0.022^{\mathrm{a}}$ \\
\hline Public official & 19 & & & 22 & & & \\
\hline \multicolumn{8}{|l|}{ Manager } \\
\hline Yes & 31 & & & 15 & & & $0.415^{\mathrm{a}}$ \\
\hline No & 120 & & & 77 & & & \\
\hline \multicolumn{8}{|l|}{ Company size } \\
\hline Small & 43 & & & 26 & & & $0.999^{\mathrm{a}}$ \\
\hline Middle & 62 & & & 38 & & & \\
\hline Large & 46 & & & 28 & & & \\
\hline Working hours/month & 151 & 159.2 & $(61.9)$ & 92 & 160.2 & $(59.4)$ & $0.901^{\mathrm{b}}$ \\
\hline \multicolumn{8}{|l|}{$\begin{array}{l}\text { Awareness/presence of systems for } \\
\text { return to work }\end{array}$} \\
\hline \multicolumn{8}{|l|}{ Financial compensation } \\
\hline Present & 113 & & & 68 & & & $0.294^{\mathrm{a}}$ \\
\hline Absent & 25 & & & 11 & & & \\
\hline Don’t know & 13 & & & 13 & & & \\
\hline \multicolumn{8}{|l|}{ Gradual resumption } \\
\hline Present & 79 & & & 44 & & & $0.176^{\mathrm{a}}$ \\
\hline Absent & 43 & & & 21 & & & \\
\hline Don’t know & 29 & & & 27 & & & \\
\hline \multicolumn{8}{|l|}{ Trial attendance } \\
\hline Present & 52 & & & 29 & & & $0.758^{\mathrm{a}}$ \\
\hline Absent & 47 & & & 27 & & & \\
\hline Don't know & 52 & & & 36 & & & \\
\hline Months of financial compensation & 115 & 14.5 & $(14.3)$ & 71 & 11.7 & $(11.1)$ & $0.139^{\mathrm{b}}$ \\
\hline
\end{tabular}

${ }^{\mathrm{a}}$ Chi-square test. ${ }^{\mathrm{b}}$ Unpaired $t$-test. SD, standard deviation.

Hypothesis 2 was "Workers whose workplaces have financial compensation, gradual resumption, and trial attendance systems will have low sickness presenteeism". This hypothesis was also not supported. Contrary to our expectations, awareness of gradual resumption and the duration of financial compensation were risk factors for presenteeism.

Some studies have shown that high levels of work engagement increase well-being and decrease the risk of illness ${ }^{22,23)}$. Therefore, we suspected that sickness presenteeism would be low if workers fully understood and had an interest in the company or systems of work engagement; however, in the present study, no relationship was observed between low sickness presentation and awareness of systems for return to work. A relationship was seen between high sickness presenteeism and awareness of gradual resumption systems. It seems natural that workers with high sickness presenteeism have better knowledge about gradual resumption systems because many of them have a history of long-term sick leave. A relationship was also seen between high sickness presenteeism and employment in a private company. This suggests that employees of private companies in Japan are frequently attending work despite feeling they should take sick leave.

On the other hand, although financial compensation systems are important for securing workers' liveli- 
Table 3. Odds ratio for each factor as related to high sickness presenteeism

\begin{tabular}{|c|c|c|c|c|c|c|c|c|}
\hline & \multicolumn{2}{|c|}{ Model $1 \quad(n=243)$} & \multicolumn{2}{|c|}{ Model 2 (n=147) } & \multicolumn{2}{|c|}{ Model $3 \quad(n=135)$} & \multicolumn{2}{|c|}{ Model $4(n=186)$} \\
\hline & $\begin{array}{l}\text { Odds } \\
\text { ratio }\end{array}$ & $95 \% \mathrm{CI}$ & $\begin{array}{l}\text { Odds } \\
\text { ratio }\end{array}$ & $95 \% \mathrm{CI}$ & $\begin{array}{l}\text { Odds } \\
\text { ratio }\end{array}$ & $95 \% \mathrm{CI}$ & $\begin{array}{l}\text { Odds } \\
\text { ratio }\end{array}$ & $95 \% \mathrm{CI}$ \\
\hline Sex (female to male) & 1.21 & [0.59-2.49] & 1.30 & {$[0.47-3.63]$} & 1.31 & [0.44-3.95] & 1.49 & [0.61-3.63] \\
\hline Age & 0.99 & [0.96-1.02] & 0.99 & {$[0.95-1.04]$} & 0.99 & [0.94-1.03] & 1.00 & [0.96-1.04] \\
\hline Company size & 0.96 & {$[0.67-1.38]$} & 0.95 & {$[0.59-1.52]$} & 1.00 & {$[0.60-1.67]$} & 0.99 & {$[0.64-1.54]$} \\
\hline Private company & 2.25 & [1.11-4.57] & 2.26 & {$[0.93-5.47]$} & 2.93 & {$[1.13-7.57]$} & 2.57 & [1.10-5.99] \\
\hline Managerial role & 1.21 & [0.59-2.49] & 0.95 & {$[0.41-2.21]$} & 1.08 & {$[0.43-2.67]$} & 1.21 & {$[0.54-2.74]$} \\
\hline Working hours & 1.00 & [0.99-1.00] & 1.00 & [0.99-1.01] & 1.00 & [0.99-1.01] & 1.00 & [0.99-1.00] \\
\hline \multicolumn{9}{|c|}{ Awareness of systems for return to work } \\
\hline Financial compensation & 1.52 & [0.58-3.99] & - & - & - & - & - & - \\
\hline Gradual resumption & 1.70 & {$[0.70-4.11]$} & - & - & - & - & 3.89 & {$[1.02-14.81]$} \\
\hline Trial attendance & 0.87 & [0.42-1.82] & - & - & - & - & 0.81 & {$[0.28-2.36]$} \\
\hline \multicolumn{9}{|l|}{ Presence of systems for return to work } \\
\hline Financial compensation & - & - & $0.67^{\mathrm{a}}$ & {$[0.24-1.92]$} & $0.47^{\mathrm{a}}$ & {$[0.15-1.54]$} & $0.46^{\mathrm{b}}$ & {$[0.17-1.23]$} \\
\hline Gradual resumption & - & - & $0.91^{\mathrm{a}}$ & {$[0.35-2.38]$} & $0.75^{\mathrm{a}}$ & {$[0.27-2.11]$} & $0.60^{\mathrm{b}}$ & {$[0.24-1.51]$} \\
\hline Trial attendance & - & - & $1.31^{\mathrm{a}}$ & {$[0.50-3.44]$} & $1.38^{\mathrm{a}}$ & {$[0.52-3.70]$} & $1.31^{\mathrm{b}}$ & {$[0.52-3.32]$} \\
\hline Months of financial compensation & - & - & & & 1.03 & [0.99-1.07] & 1.04 & [1.01-1.07] \\
\hline
\end{tabular}

Binary logistic regression analysis was performed. 95\% CI, 95\% confidence interval. a Presence of systems for return to work compared with absence. ${ }^{b}$ Presence of systems for return to work compared with absence and do not know about the existence of the systems. Awareness of financial compensation was ruled out from the regression coefficient in model 4 . To combine the awareness and presence of systems variables, the response "I am unaware of these systems" was combined with that indicating the absence of systems for return to work in model 4.

hoods, a long duration of financial compensation may have a negative effect on sickness presenteeism. In a previous study, financial stress appeared to be related to sickness presenteeism ${ }^{24)}$; however, in the present study, sickness presenteeism increased with increases in the level of financial compensation. This suggests that the duration of financial compensation plays an important role in relation to sickness presenteeism. Arends et al. reported that the incidence of relapse of mental illness became greater as the size of company increased $^{25)}$, and Rost et al. reported that the economic impact of a loss in productivity varies according to company $\operatorname{size}^{26)}$. In the present study, no relationship was observed between sickness presenteeism and company size.

\section{Limitations}

This study had several limitations. First, the participants were limited to those who had access to the Internet, which may have created a selection bias. Second, the survey questions asked about events occurring in the preceding 12 months, which may have introduced a recall bias. Third, we did not consider the degree of involvement of industrial health personnel, or personality factors of individual workers such as financial status, marital status, and educational level. The duration of time until return to work has been reported to be related to health-related quality of life $\mathrm{e}^{27)}$ and severity of illness ${ }^{28)}$; however, these factors were not investigated in the present study. The question regarding awareness of systems for return to work only asked if workers were aware of a system; whether they actually understood the system was not investigated. In addition, the prevalence of sickness presenteeism was not very low; therefore, we did not consider ORs as indicating the relative risk. These methodology-related problems can be minimized by conducting a survey on all employees of more than one company.

\section{Conclusion}

The present study is expected to contribute to research involving human resources and occupational health. The results suggest that high sickness presenteeism is related to employment in a private company, awareness of gradual resumption systems, and a long duration of financial compensation. No relationship was found between sickness presenteeism and the presence of systems for return to work. Further study is needed to investigate what kind of system can best promote low sickness presenteeism.

Disclosure of funding: This work was supported in part by JSPS KAKENHI Grant No. 24689024. 
Conflict of interest: The authors declare that they have no competing interests.

Acknowledgments: The authors wish to thank all workers who participated in the survey.

\section{References}

1) Hees HL, de Vries G, Koeter MW, Schene AH. Adjuvant occupational therapy improves long-term depression recovery and return-to-work in good health in sick-listed employees with major depression: results of a randomised controlled trial. Occup Environ Med 2013; 70: 252-60.

2) Bakker IM, Terluin B, van Marwijk HW, et al. A cluster-randomised trial evaluating an intervention for patients with stress-related mental disorders and sick leave in primary care. PLoS Clin Trials 2007; 2 : e26. (doi:10.1371/journal.pctr).

3) International Labour Organization. Job stress: The $20^{\text {th }}$ century disease. Geneva: United Nations Labour Office; 1993. World Labour Report, no 6.

4) Aronsson G, Gustafsson K, Dallner M. Sick but yet at work. An empirical study of sickness presenteeism. J Epidemiol Community Health 2000; 54: 502-9.

5) Aronsson G, Gustafsson K. Sickness presenteeism: prevalence, attendance-pressure factors, and an outline of a model for research. J Occup Environ Med 2005; 47: 958-66.

6) Gustafsson K, Marklund S. Associations between health and combinations of sickness presence and absence. Occup Med (Lond) 2014; 64: 49-55.

7) Janssens H, Clays E, De Clercq B, De Bacquer D, Braeckman L. The relation between presenteeism and different types of future sickness absence. $\mathrm{J}$ Occup Health 2013; 55: 132-41.

8) Cocker F, Martin A, Scott J, Venn A, Otahal P, Sanderson K. Factors associated with presenteeism among employed Australian adults reporting lifetime major depression with 12-month symptoms. J Affect Disord 2011; 135: 231-40.

9) Conway PM, Hogh A, Rugulies R, Hansen ÅM. Is sickness presenteeism a risk factor for depression? A Danish 2-year follow-up study. J Occup Environ Med 2014; 56: 595-603.

10) Wada K, Arakida M, Watanabe R, Negishi M, Sato J, Tsutsumi A. The economic impact of loss of performance due to absenteeism and presenteeism caused by depressive symptoms and comorbid health conditions among Japanese workers. Ind Health 2013; 51: 482-9.

11) Furukawa TA, Horikoshi M, Kawakami N, et al. Telephone cognitive-behavioral therapy for subthreshold depression and presenteeism in workplace: a randomized controlled trial. PLoS One 2012; 7: e35330. (doi: 10.1371/journal. pone.0035330).

12) Coffeng JK, Hendriksen IJ, Duijts SF, Twisk JW, van Mechelen W, Boot CR. Effectiveness of a combined social and physical environmental inter- vention on presenteeism, absenteeism, work performance, and work engagement in office employees. J Occup Environ Med 2014; 56: 258-65.

13) Cocker F, Martin A, Scott J, Venn A, Otahal P, Sanderson K. Factors associated with presenteeism among employed Australian adults reporting lifetime major depression with 12-month symptoms. J Affect Disord 2011; 135: 231-40.

14) Rantanen I, Tuominen R. Relative magnitude of presenteeism and absenteeism and work-related factors affecting them among health care professionals. Int Arch Occup Environ Health 2011; 84: 225-30.

15) Suzuki T, Miyaki K, Song Y, et al. Relationship between sickness presenteeism (WHO-HPQ) with depression and sickness absence due to mental disease in a cohort of Japanese workers. J Affect Disord 2015; 180: 14-20. (doi: 10.1016/ j.jad.2015.03.034).

16) Taloyan M, Aronsson G, Leineweber C, Magnusson Hanson L, Alexanderson K, Westerlund H. Sickness presenteeism predicts suboptimal self-rated health and sickness absence: a nationally representative study of the Swedish working population. PLoS One 2012; 7: e44721. (doi: 10.1371/journal. pone.0044721).

17) Macromill. [Online]. 2014 [cited 2014 Jun 30]; Available from: URL: http://www.macromill.com/

18) Faul F, Erdfelder E, Lang AG, Buchner A. G*Power 3: a flexible statistical power analysis program for the social, behavioral, and biomedical sciences. Behav Res Methods 2007; 39: 175-91.

19) Netterstrøm B, Conrad N, Bech P, et al. The relation between work-related psychosocial factors and the development of depression. Epidemiol Rev 2008; 30: 118-32.

20) Takao S, Tsutsumi A, Nishiuchi K, Mineyama S, Kawakami N. Effects of the job stress education for supervisors on psychological distress and job performance among their immediate subordinates: a supervisor-based randomized controlled trial. J Occup Health 2006; 48: 494-503.

21) Tsutsumi A, Takao S, Mineyama S, Nishiuchi K, Komatsu H, Kawakami N. Effects of a supervisory education for positive mental health in the workplace: a quasi-experimental study. J Occup Health 2005; 47: 226-35.

22) Shimazu A, Schaufeli WB, Kamiyama K, Kawakami N. Workaholism vs. work engagement: the two different predictors of future well-being and performance. Int J Behav Med 2014 Apr 3. [Epub ahead of print] (doi: 10.1007/s12529-014-9410-x).

23) Nakagawa $Y$, Inoue $A$, Kawakami $N$, et al. Job demands, job resources, and job performance in Japanese workers: a cross-sectional study. Ind Health. 2014 Jul 11 [Epub ahead of print] (doi: 10.2486/indhealth.2014-0036).

24) Callen BL, Lindley LC, Niederhauser VP. Health risk factors associated with presenteeism in the workplace. J Occup Environ Med 2013; 55: 1312-7. 
25) Arends I, van der Klink JJ, van Rhenen W, de Boer MR, Bültmann U. Predictors of recurrent sickness absence among workers having returned to work after sickness absence due to common mental disorders. Scand J Work Environ Health 2014; 40: 195-202.

26) Rost $\mathrm{KM}$, Meng $\mathrm{H}, \mathrm{Xu}$ S. Work productivity loss from depression: evidence from an employer survey. BMC Health Serv Res 2014; 14: 597. (doi: 10.1186/ s12913-014-0597-y).
27) Vemer P, Bouwmans CA, Zijlstra-Vlasveld MC, van der Feltz-Cornelis CM, Hakkaart-van Roijen L. Let's get back to work: survival analysis on the return-to-work after depression. Neuropsychiatr Dis Treat 2013; 9: 1637-45.

28) Hees HL, Koeter MW, Schene AH. Predictors of long-term return to work and symptom remission in sick-listed patients with major depression. J Clin Psychiatry 2012; 73: e1048-55. (doi: 10.4088/ JCP.12m07699). 